\title{
Association of Plectin with Z-Discs Is a Prerequisite for the Formation of the Intermyofibrillar Desmin Cytoskeleton
}

\author{
Rolf Schröder, Dieter O. Fürst, Christian Klasen, Jens Reimann, Harald Herrmann, \\ and Peter F. M. van der Ven
}

Department of Neurology (RS, CK, JR), University Hospital Bonn, Bonn; Department of Cell Biology (DOF, PFMVDV), University of Potsdam, Potsdam; and Division of Cell Biology (HH), German Cancer Research Center, Heidelberg, Germany

\begin{abstract}
SUMMARY: Plectin is a high-molecular mass protein $(\approx 500 \mathrm{kd})$ that binds actin, intermediate filaments, and microtubules. Mutations of the plectin gene cause a generalized blistering skin disorder and muscular dystrophy. In adult muscle, plectin is colocalized with desmin at structures forming the intermyofibrillar scaffold and beneath the plasma membrane. To study the involvement of plectin in myofibrillogenesis, we analyzed the spatial and temporal expression patterns of plectin in cultured differentiating human skeletal muscle cells and its relationship to desmin intermediate filaments during this process. Northern and Western blot analyses demonstrated that at least two different plectin isoforms are expressed at all developmental stages from proliferating myoblasts to mature myotubes. Using immunocytochemistry, we show that the localization of plectin dramatically changes from a network-like distribution into a cross-striated distribution during maturation of myocytes. Double immunofluorescence experiments revealed that desmin and plectin are colocalized in premyofibrillar stages and in mature myotubes. Interestingly, plectin was often found to localize to the periphery of Z-discs during the actual alignment of neighboring myofibrils, and an obvious cross-striated plectin staining pattern was observed before desmin was localized in the Z-disc region. We conclude that the association of plectin with Z-discs is an early event in the lateral alignment of myofibrils that precedes the formation of the intermyofibrillar desmin cytoskeleton. (Lab Invest 2000, 80:455-464).
\end{abstract}

$P$ lectin is a high-molecular mass protein $(\approx 500 \mathrm{kd})$ that is abundantly expressed in a wide variety of mammalian tissues and cell types (Wiche, 1989; Wiche, 1998; Wiche et al, 1983 ). In humans, plectin is encoded by a single copy gene on chromosome 8q24 (Liu et al, 1996, McLean et al, 1996; Schröder et al, 1997). The cDNA of plectin shows sequence similarity to bullous pemphigoid antigen 1 (BPAG-1), periplakin, envoplakin, and desmoplakin (Liu et al, 1996; Ruhrberg et al, 1996; Ruhrberg et al, 1997; Smith et al, 1996; Stappenbeck et al, 1993; Yang et al, 1996). These proteins, which were grouped as members of the plakin gene family, are known to codistribute with intermediate filaments (IF) and their plasma membrane adhesion sites (eg, hemidesmosomes, desmosomes), but they differ in their individual expression patterns and their binding properties to additional cytoskeletal elements (Ruhrberg and Watt, 1997).

Received September 14, 1999

This work was supported in part by a University of Bonn Center Grant (Bonfor 111/04). R. Schröder was supported by a grant of the Deutsche Forschungsgemeinschaft (Schr 561-2).

Address reprint requests to: Dr. P. F. M. van der Ven, Department of Cell Biology, University of Potsdam, Lennéstr.7a, D-14471 Potsdam, Germany. Fax: 0049331977 4861; E-mail pvdven@rz.uni-potsdam.de
Plectin, by far the best characterized member of the plakin gene family, was shown to contain a vimentin binding site in its carboxyterminal region and an actin-binding motif in its amino terminal region that shares a high degree of sequence similarity with actin-binding domains found in $\alpha$-actinin, utrophin, and dystrophin (Elliott et al, 1997; McLean et al, 1996; Wiche et al, 1993). Its functional relationship to the microfilament system is further underlined by the observation that plectin codistributes with actincontaining junctional complexes, such as focal contacts and stress fibers (Andrä et al, 1998; Seifert et al, 1992). Moreover, biochemical and ultrastructural studies demonstrated that plectin may bind to microtubules, $\alpha$-spectrin, and integrin $\beta 4$ and to microtubuleassociated proteins (Herrmann and Wiche, 1987; Niessen et al, 1997; Rezniczek et al, 1998; Svitkina et al, 1996).

Its postulated role as an essential and versatile cytoskeletal linker protein is highlighted by recent studies showing that mutations of the human plectin gene as well as targeted ablation of plectin in mice cause a generalized blistering skin disorder and structural abnormalities in striated muscles (Andrä et al, 1997; Gache et al, 1996; McLean et al, 1996; Smith et al, 1996). The observed structural failure of skin and striated muscle tissue in man and mice strongly indicates that plectin has a pivotal role in stabilizing and 
strengthening cells that endure mechanical stress; however, it is not clear how this essential function is accomplished.

While the epidermal phenotype in patients suffering from the autosomal recessive disorder epidermolysis bullosa simplex with muscular dystrophy (EBS-MD) could be attributed to an impaired cytokeratinhemidesmosome linkage (Smith et al, 1996), the mechanisms leading to the severe dystrophic changes in skeletal muscle remain elusive. Muscle biopsies from EBS-MD patients demonstrate an increased variability of fiber-type diameters, necrotic and hypertrophied fibers, and a disorganization of myofibrils and sarcomeres (Doriguzzi et al, 1993; Gache et al, 1996). In addition, an aberrant desmin staining with lack of labeling at the Z-disc region and increased subsarcolemmal immunoreactivity have been reported (Gache et al, 1996). The latter observation might serve as indirect evidence that the lack of plectin interferes with the structural integrity of the desmin cytoskeleton.

Recently, the ultrastructural distribution of plectin was described in adult human (Schröder et al, 1997; Schröder et al, 1999) and rat skeletal muscles (Hijikata et al, 1999). Immunoelectron microscopy and confocal laser scanning microscopy were used to show that plectin was localized at structures that spanned between neighboring Z-discs of adjacent myofibrils, at filamentous bridges between Z-discs of peripheral myofibrils and the overlaying sarcolemma (Hijikata et al, 1999; Schröder et al, 1999), and at regularly spaced intervals along the cytoplasmic face of the plasma membrane (Schröder et al, 1999). At the former two locations, a colocalization of plectin and desmin IF was demonstrated.

To gain insight into the role of plectin during skeletal muscle fiber development, we studied the expression and localization patterns of plectin in differentiating cultured human skeletal muscle cells. We describe the temporal and spatial expression patterns of plectin and its relationship to both developing myofibrils and desmin IF. Our results suggest that plectin might determine the striking reorganization of the desmin filament system characteristic for developing muscle cells and that the association of plectin with Z-discs might be involved in the lateral alignment of myofibrils.

\section{Results}

Expression of Plectin Messenger Ribonucleic Acid and Protein in Differentiating Cultured Human Skeletal Muscle Cells. The temporal expression pattern of plectin was analyzed both at the transcript level by Northern blot and at the protein level by Western blot. A specific probe corresponding to the $3^{\prime}$-end of the human plectin cDNA was used to probe Northern blots of total RNA prepared from proliferating myoblasts and differentiating myotubes at various developmental stages ranging from 8 hours to 8 days after induction of differentiation. This revealed the presence of two distinct plectin transcripts of approximately 15 kilobase (kb) and $13 \mathrm{~kb}$, respectively, at all developmental stages examined (Fig. 1). The lack of molecular mass markers in this size range, however, makes an accurate determination difficult. The markedly less pronounced signal intensity of the smaller transcript

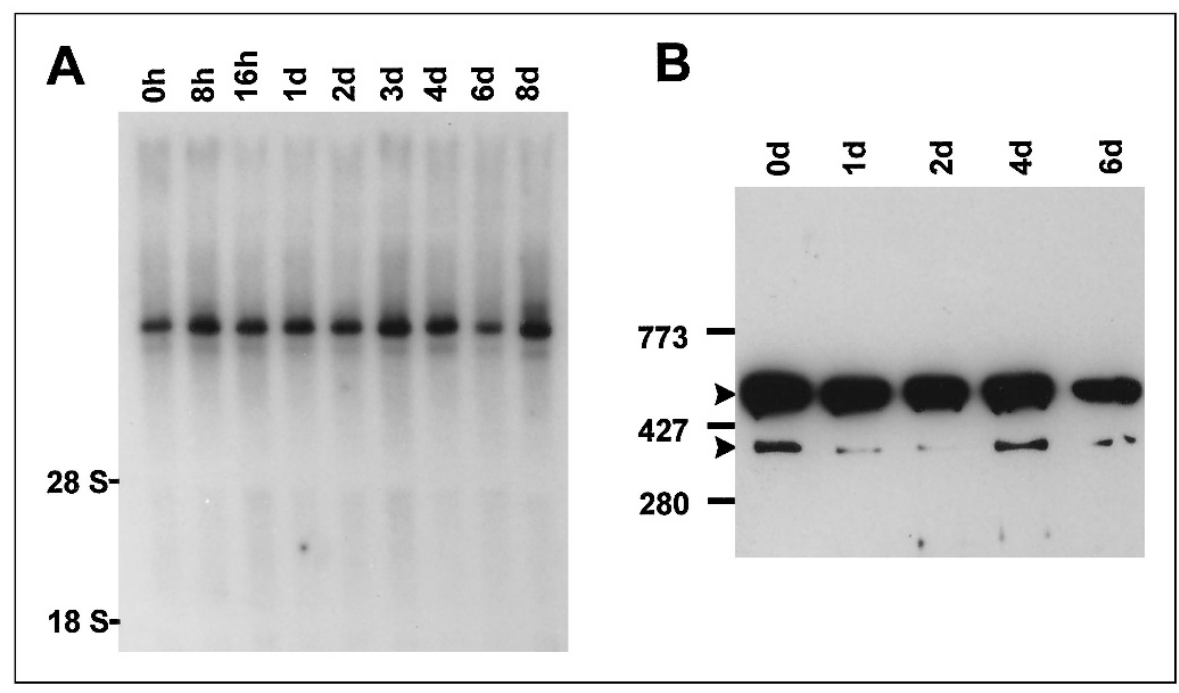

Figure 1.

Expression analysis of plectin at the transcript and protein levels in differentiating cultured human skeletal muscle cells. Panel A, Northern blot describing the temporal expression pattern of plectin messenger ribonucleic acid (mRNA). Total RNA isolated from cultured human skeletal muscle cells differentiated for the time indicated at the top of each lane was separated by agarose gel electrophoresis and was transferred to a nylon membrane. The blot was hybridized with a cDNA probe specific for the $3^{\prime}$ untranslated region of the plectin mRNA. Note that in all developmental stages, examined plectin transcripts of approximately 15 and 13 kd were detected. Panel B, Western blot analysis of plectin expression pattern. Total protein extracts from cultured human skeletal muscle cells differentiated for the time indicated at the top of each lane were separated by polyacrylamide gel electrophoresis and were transferred to a PVDF membrane. The blot was incubated with the P2 plectin antiserum that recognizes a part of plectin expressed in all plectin isoforms known to date. At the left, the positions of the signals obtained after incubation of the same blots with antibodies specific for nebulin ( $773 \mathrm{kd})$, dystrophin ( $427 \mathrm{kd})$, and filamin $(280 \mathrm{kd})$ are marked. Note that in the extracts from all developmental stages, two plectin variants are detected; their molecular masses are estimated to be $520 \mathrm{kd}$ and $360 \mathrm{kd}$, respectively. 
compared with that of its major counterpart indicates that the quantities of the detected transcripts differed considerably. With regard to the temporal expression of plectin, the relative amounts of the two transcripts remained constant throughout all stages of muscle differentiation; ie, no plectin transcript could be identified that is expressed solely in either nondifferentiated or differentiated cells.

Subsequently, the expression of plectin was analyzed at the protein level. A Western blot of total protein extracts prepared from proliferating myoblasts, mature myotubes after 6 days of differentiation, and various intermediate developmental stages was incubated with P2 plectin antiserum; plectin was revealed at all stages of muscle cell differentiation (Fig. 1B). In addition to the immunolabeling of a predominant high molecular mass plectin isoform, $\mathrm{P} 2$ reacted with a second considerably smaller and lessprominent band. No reactivity with any other protein band was observed. To analyze the approximate molecular masses of both plectin isoforms, we com- pared their migration patterns with those obtained by labeling with antibodies specific for filamin (280 kd), dystrophin $(427 \mathrm{kd})$, and nebulin $(773 \mathrm{kd})$. Using the signals obtained by all antibodies as molecular mass markers, we estimated the molecular mass of the major plectin isoform to be approximately $520 \mathrm{kd}$ and that of the minor isoform to be $360 \mathrm{kd}$. Taken together, our Northern and Western blot data indicate that the expression of at least two distinct high molecular mass plectin isoforms is highly conserved during all stages of in vitro human skeletal muscle cell differentiation.

Plectin Distribution Changes Dramatically During Myocyte Differentiation. To provide insight into the spatial and temporal distribution of plectin during early developmental stages of muscle differentiation, human skeletal muscle cells fixed at several developmental stages were stained with the P2 antiserum. In undifferentiated proliferating myoblasts, plectin was localized in a filamentous network-like pattern in all cells (Fig. 2A). During further development, this pattern
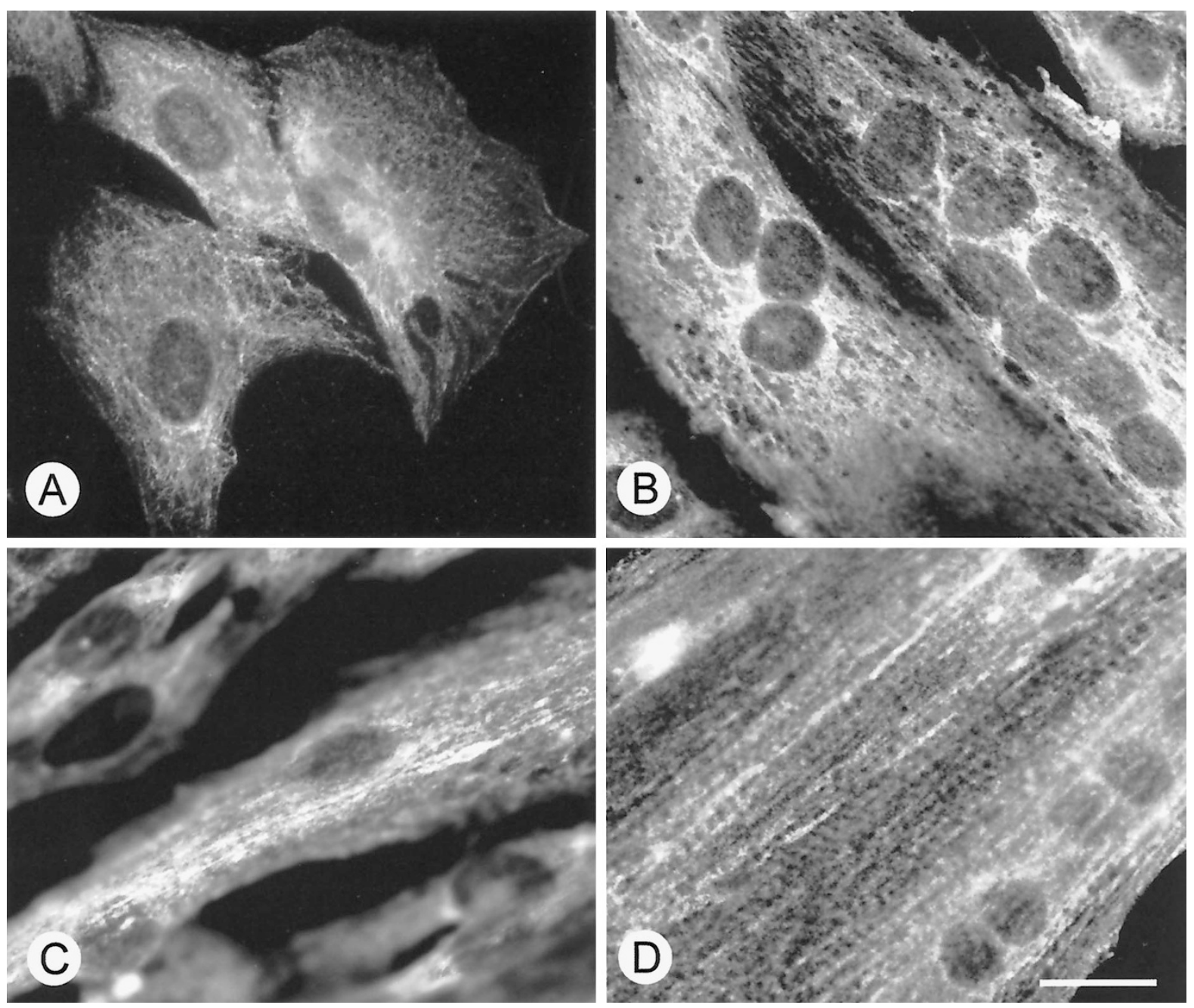

\section{Figure 2.}

Immunolocalization of plectin in cultured human skeletal muscle cells. Human skeletal muscle cells differentiated for 0 (A), 2 (B), 4 (C), or 6 (D) days were stained with the P2 plectin antiserum. In proliferating cells, plectin is detected in a fine network-like distribution (A). In young myotubes, plectin-containing filaments are more longitudinally oriented in the cytoplasm (B) and at the level of the sarcolemma (C), while in fully differentiated myotubes, plectin is detected in a cross-striated staining pattern (D). Bar: $20 \mu \mathrm{m}$. 
of randomly oriented cytoplasmatic filaments changed dramatically. Two days (Fig. 2B) and 4 days (Fig. 2C) subsequent to the induction of differentiation, plectin was found predominantly in longitudinally oriented filaments. Particularly at the 4-day stage, some filaments were localized at the sarcolemma (Fig. 2C). Upon further differentiation to mature myotubes, plectin was predominantly localized in a clear crossstriated pattern (Fig. 2D).

To examine whether plectin might be involved in the assembly or lateral alignment of myofibrils, differentiating human myocytes were double-stained with plectin antibody P2 and titin antibody T12; the latter served as a marker for the Z-discs of myofibrils. In the analysis, proliferating myoblasts that showed network-like plectin staining did not yet contain detectable amounts of titin (Fig. 3, A and B). After the change to the low-nutrition culture medium, isolated cells became spindle-shaped. In due course, these cells turned into nonproliferating elongated mononuclear cells that subsequently aligned and fused to form multinucleated myotubes. During these early developmental stages, titin staining was mainly associated with longitudinally oriented stress fiber-like structures (SFLS) that did not seem to be connected with the now longitudinally oriented plectin-containing filaments (Fig. 3, C and D). Upon further maturation, these SFLS changed into striated but separate myofibrils (Fig. 4, A and C). Fine plectin-containing threads oriented parallel to these cross-striated (but not yet aligned) myofibrils were revealed (Fig. 4, B and C). A closer look showed that plectin was concentrated in thickenings at these threads (Fig. 4C). Confocal laser scanning microscopy with higher sensitivity and resolution precisely localized these structures. Plectin was concentrated exactly between the Z-discs of neighboring myofibrils (Fig. 4, D to F), which indicates that the localization of plectin to the Z-disc region of myofibrils coincides with the lateral alignment of the Z-discs of preexisting myofibrils.

\section{Plectin Colocalizes with Desmin Intermediate Filaments During Early and Very Late Stages of Muscle Differentiation}

The distribution of plectin was also compared to that of desmin, the IF protein known to be colocalized with plectin in the intermyofibrillar space at the level of Z-discs in adult skeletal muscle. In line with earlier reports (Van der Ven et al, 1992; Van der Ven et al, 1993), our immunohistochemical analysis of human myoblasts cultured in high-nutrition medium and fixed before reaching confluence revealed a filamentous, network-like desmin staining pattern (Fig. 5A) and a similar vimentin (not shown) staining pattern in more than $95 \%$ and $100 \%$ of the cells, respectively. Using double immunofluorescence with desmin antibodies and the P2 antiserum, we noted that plectin immuno-
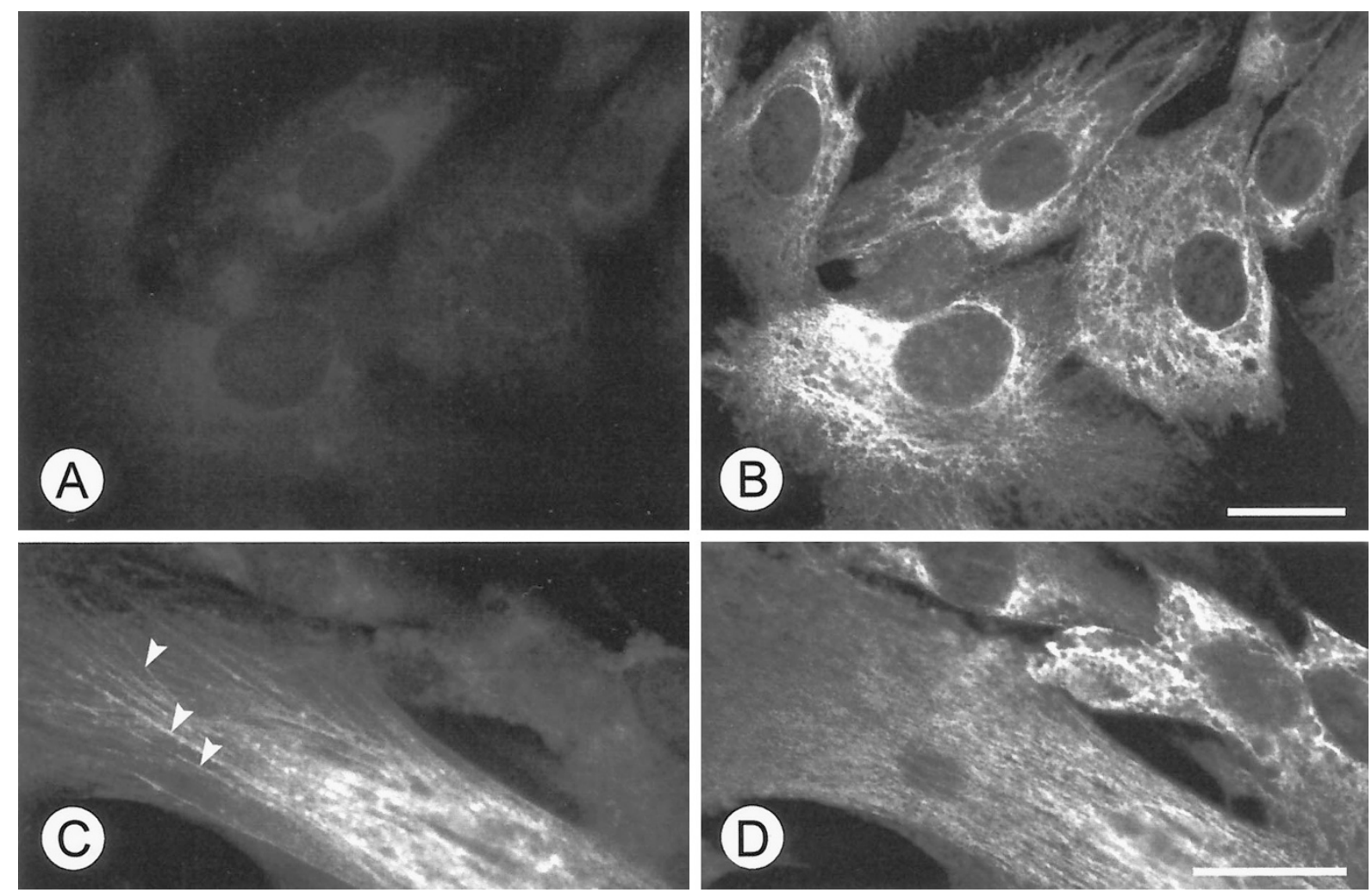

\section{Figure 3.}

Immunolocalization of plectin and titin in early stages of human skeletal muscle cell differentiation. Human skeletal muscle cells differentiated for 0 days (A and B) or 2 days $(C$ and $D)$ were double-stained with the $P 2$ plectin antiserum ( $B$ and $D)$ and titin antibody $T 12$ ( $A$ and $C)$. In proliferating cells, titin is not yet expressed (A), while plectin is distributed in a network-like pattern (B). After 2 days of differentiation, titin is found in longitudinally oriented cables, or "stress fiber-like structures" (arrows, C). No obvious colocalization with plectin-containing filaments (D) is observed. Bar: $20 \mu \mathrm{m}$. 

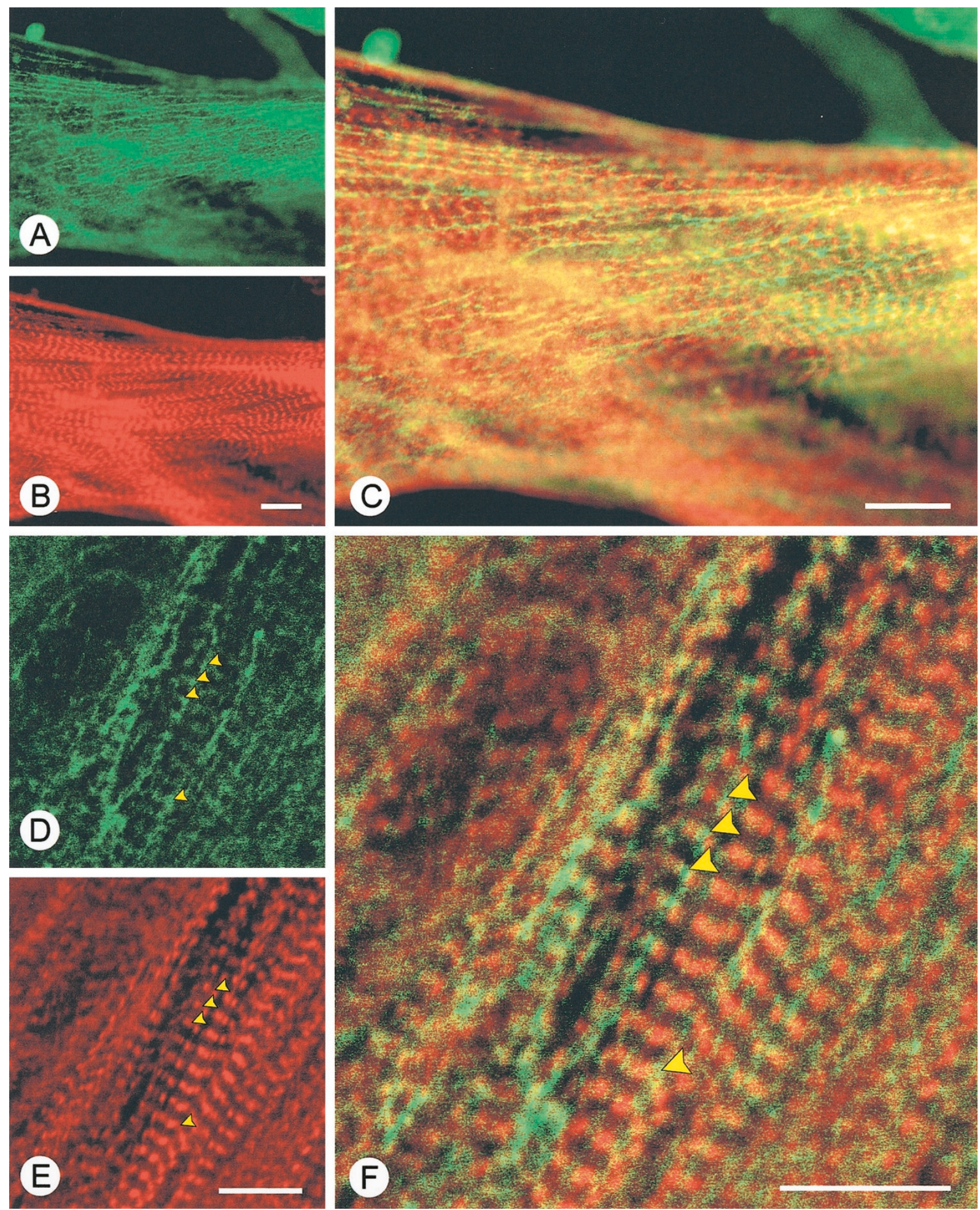

E

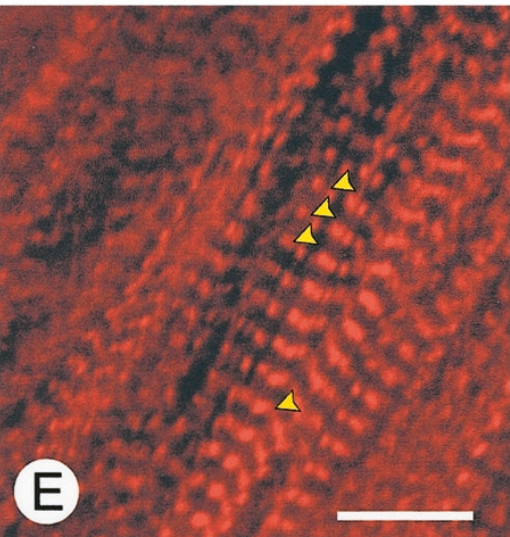

\section{Figure 4.}

Immunolocalization of plectin and titin in advanced stages of human skeletal muscle cell differentiation. Human skeletal muscle cells differentiated for 4 days (A, B, and $C$ ) or 6 days $(D, E$, and $F$ ) were double-stained with the P2 plectin antiserum ( $A$ and $D)$ and titin antibody $T 12(B$ and $E)$. After 4 days of differentiation, titin is found in mature myofibrils at its characteristic localization in Z-discs, which results in a striated staining pattern of individual myofibrils (B). In the same cell, plectin is localized in fine threads (A). The further-enlarged merged picture (C) shows that these plectin threads (green) run parallel to the myofibrils (red). Note that the fibrils are irregularly shaped and that at certain positions, the fibrils seem thicker (A and $C$ ). At higher magnification with a confocal laser scanning microscope, the thickenings (green) are confirmed ( $\mathrm{D}$ and F) and can be localized exactly between the Z-discs (E and F) of neighboring myofibrils (arrows in D, E, and F), which are identified by the red titin T12 staining. Bars: $20 \mu \mathrm{m}$. 

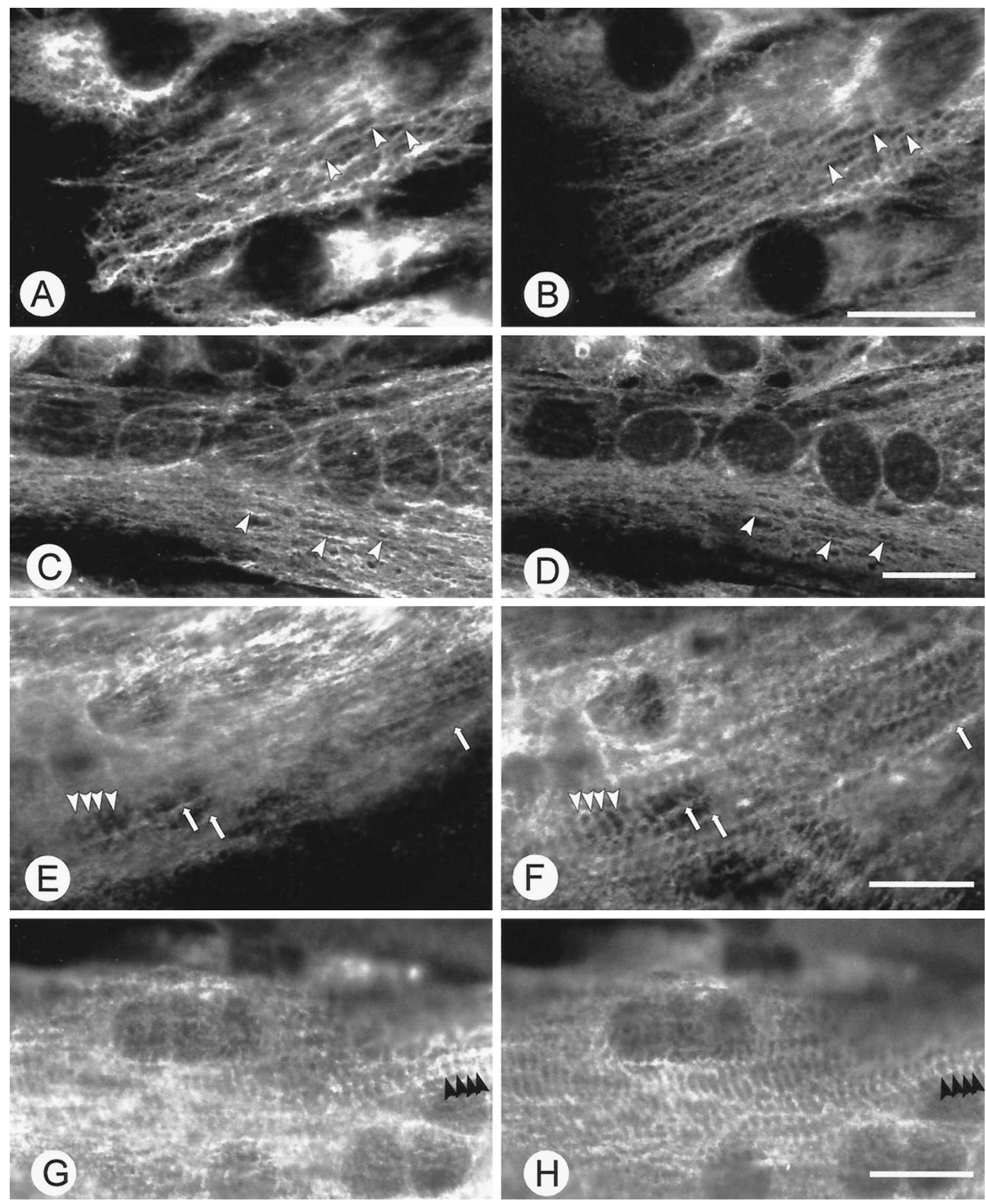

\section{Figure 5.}

Immunolocalization of plectin and desmin in cultured human skeletal muscle cells. Human skeletal muscle cells differentiated for $0(A$ and $B), 2(C$ and $D), 5$ (E and $F)$, and $6(G$ and $H)$ days were double-stained with the $P 2$ antiserum $(B, D, F$, and $H)$ and a rabbit polyclonal antibody specific for desmin ( $A, C, E$, and $G)$. In proliferating cells, the distributions of desmin and plectin are virtually identical (arrows in A and B). In young myotubes in which the plectin-containing filaments are more longitudinally oriented (D), a remarkable codistribution of desmin and plectin (arrows in C and D) that is also evident after 5 days of differentiation (arrows in $\mathrm{E}$ and F) can be observed. At this developmental stage, plectin shows a distinct striated staining pattern in individual myotubes (arrows in F), whereas in the same myotube, no such labeling is observed with the desmin antiserum (arrows in E). Only in mature myotubes observed in our cultures after 6 or more days of differentiation are both desmin and plectin found in an identical cross-striated pattern (arrows in G and H). Bars: $20 \mu \mathrm{m}$.

reactivity was hardly distinguishable from that of desmin; ie, both proteins were distributed in at least very similar filamentous cytoplasmatic networks in proliferating myoblasts and nonproliferating, elon- gated mononuclear cells (Fig. 5, A and B). In early myotubes, where the plectin containing filaments were oriented more longitudinally, the desmin/plectin colocalization was still striking but not complete (Fig. 5, C 
and D), whereas in myotubes differentiated for 5 days, an obvious cross-striated plectin distribution were observed, although desmin was still localized in longitudinal filaments (Fig. 5, E and F). Only in the most mature myotubes (ie, after 6 or more days of differentiation) plectin and desmin were observed in identical cross-striated staining patterns (Fig. 5, G and H).

\section{Discussion}

Plectin, the most widely and abundantly expressed member of the plakin gene family, was proposed to serve as a cross-link between the microfilament and IF cytoskeleton (Ruhrberg and Watt, 1997). Its pivotal role in strengthening cells against mechanical stress is highlighted by recent studies showing that mutations of the human plectin gene (Chavanas et al, 1996; Dang et al, 1998; Gache et al, 1996; McLean et al, 1996; Pulkkinen et al; 1996, Smith et al, 1996; Takizawa et al, 1999) and the targeted ablation of its murine analog (Andrä et al, 1997) give rise to generalized skin blistering and to structural alterations of striated muscles. Whereas the integral role of plectin in the anchorage of keratin IF to hemidesmosomes in epithelial cells is well characterized, its normal function in striated muscles and the mechanisms leading to the dystrophic process in skeletal muscle tissue remain elusive. It was recently demonstrated that plectin and desmin colocalize at the level of Z-discs and beneath the plasma membrane in human (Schröder et al, 1997; Schröder et al, 1999) and rat skeletal muscle (Hijikata et al, 1999). Furthermore, the immunohistochemical analysis of skeletal muscle specimens of EBS-MD patients showed an aberrant desmin staining (Gache et al, 1996). Both findings strongly suggest that plectin has a central role in the organization of the intermyofibrillar desmin cytoskeleton. Plectin contains an IF-binding site in its carboxyterminal region, (Wiche et al, 1993) which further supports this suggestion. Because plectin also contains a functional actin binding site in its aminoterminal region (Andrä et al, 1998; Elliott et al, 1997 ) and binds to microtubules (Svitkina et al, 1996), the dystrophic skeletal muscle process in plectin deficiencies may be attributed to changes in either the desmin IF, the microfilaments, or the microtubules.

In this study, we analyzed the temporal and spatial expression patterns of plectin during various stages of in vitro muscle cell differentiation and its relationship to developing myofibrils and desmin IF. To characterize plectin expression at the transcriptional level, we performed a Northern blot analysis that used the $3^{\prime}$ end of the human plectin CDNA as a probe. This part of the plectin messenger ribonucleic acid (mRNA) molecule should, according to the current knowledge of alternative splicing of the plectin mRNA (Elliott et al, 1997; (Liu et al, 1996; McLean et al, 1996), hybridize to all plectin transcripts. Our results revealed two plectin transcripts of about 15 and $13 \mathrm{~kb}$, respectively, in all developmental stages examined. The signal intensity of the smaller isoform was considerably weaker than that of the larger variant (Fig. 1A). The analysis of plectin transcript diversity in rat skeletal muscle has revealed that plectin variants with three distinct first coding exons and variants without the rod domain may be expressed in skeletal muscle (Elliott et al, 1997). The longer transcript we detected on our Northern blot probably represents one or more splice variants bearing the rod domain, while the shorter transcript most probably encodes a plectin variant without the rod domain, which is also expressed in adult rat skeletal muscle at much lower levels.

This pattern of plectin expression is complemented by our Western blot studies. We used the plectin P2 antiserum, which is directed against the carboxyterminally situated sixth repeat domain of human plectin that is present in all predicted plectin isoforms, to demonstrate the presence of a predominant high molecular mass plectin isoform and much lower levels of another considerably smaller isoform. Gel mobilities of several other well-characterized high molecular mass proteins were used to estimate the molecular masses of both isoforms as being approximately 520 and $360 \mathrm{kd}$, respectively. After calculating the length difference of both pectin mRNAs and a comparison with the molecular masses of the proteins, one can assume that they represent isoforms with and without the rod domain.

Our data on the expression of plectin mRNA and protein in muscle cell cultures complement observations made in mature human skeletal muscle (Schröder et al, 1999). Our findings indicate that the expression of at least two high molecular mass plectin isoforms is highly conserved during all stages of differentiation ranging from proliferating myoblasts to mature human skeletal muscle tissue. This might imply that although the distribution and (probably also the function) of plectin changes dramatically during the early stages of in vitro human skeletal muscle cell differentiation (see below), no extra plectin isoform seems to be expressed. However, considering the complex nature of the exon-intron organization of mammalian plectin genes (Elliott et al, 1997; Liu et al, 1996; McLean et al, 1996; Wiche, 1998), the existence of additional splice variants in human skeletal muscle cannot be excluded. Those variants might have escaped detection in our experiments because of either low expression levels or the technical limitations in resolving plectin transcripts or polypeptides that migrate too closely. Furthermore it is probable that not all of the plectin isoforms detected in rat skeletal muscle tissue are found in cultured muscle cells, because muscle tissue consists of several other cell types in addition to myofibers. In contrast, our muscle cell cultures contained at least $95 \%$ myocytes.

This leaves the question of how plectin is differentially organized during in vitro muscle cell differentiation. In our immunofluorescence studies using plectin antiserum $\mathrm{P} 2$, all plectin isoforms known to date can be recognized. This was confirmed by the detection of comparable amounts of plectin in all developmental stages examined. However, we observed a drastic alteration in the distribution of plectin that ranged from a filamentous, network-like distribution in early developmental stages to a highly ordered cross-striated 
pattern in mature myotubes. In proliferating myoblasts, in very early myotubes, and in mature myotubes, plectin and desmin were colocalized. However, the analysis of intermediate developmental stages revealed that the staining for plectin and desmin followed a nonidentical course during this maturation process. The cross-striated plectin staining pattern clearly preceded the formation of the regularly spaced, cross-striated desmin distribution and coincided with the lateral alignment of neighboring myofibrils. These findings suggest that plectin might have a function in the spatial arrangement of the contractile apparatus, and particularly in the alignment of myofibrils and the subsequent reorganization of desmin IF. In both EBS-MD patients (Gache et al, 1996) and in mice in which the plectin gene was inactivated by heterologous recombination (Andrä et al, 1997), the assembly of myofibrils does not seem to be disturbed. In contrast, it was the lateral alignment of myofibrils that did not occur. Similarly, in EBS-MD patients it was noted that the absence of plectin was accompanied by an impaired desmin distribution: Desmin was absent from the Z-disc region and instead accumulated at the sarcolemma (Gache et al, 1996). Unfortunately, the desmin localization in muscle specimens from plectin -/- mice was not reported. Further support for the suggestion that plectin could play a role in tethering aligning myofibrils to each other and in heralding the reorganization of the IF-based cytoskeleton at the level of the Z-disc is provided by studies on skeletal muscle from desmin -/- mice. Even in the absence of desmin, interconnecting filamentous links between the Z-discs of most peripheral myofibrils and the overlaying sarcolemma were noted ( $\mathrm{Li}$ et al, 1997). These filaments, which are found between the Z-discs of neighboring myofibrils in the absence of desmin, contain plectin, whereas synemin and paranemin, which colocalize with plectin and desmin at the level of Z-discs (Bilak et al, 1998; Carlsson et al, 1999; Granger and Lazarides, 1980; Hemken et al, 1997; Price and Lazarides, 1983), were no longer detectable at this location (Carlsson et al, 1999). This implies that plectin is targeted to the Z-disc even in the absence of desmin and other IF proteins that are usually found in these structures, whereas the organization of desmin, paranemin, and synemin seems to be disturbed in the absence of plectin.

Severe structural alterations in skeletal and cardiac muscles develop in mice lacking either plectin or desmin, which suggests that these two proteins have complementary (but not interchangeable) roles in force transduction and in the maintenance of the structural integrity of striated muscle fibers. Both plectin and desmin -/- mice display histologic signs of misaligned myofibrils and focal disruptions of sarcomeres at the level of Z-discs, which indicates that these structures lacking either plectin or desmin cannot endure ongoing physical strain. The molecular basis of the desmin-Z-disc attachment is unclear, and further studies are needed to clarify the issue of whether plectin mediates the desmin attachment in a direct or indirect manner. Plectin might bind to Z-discs through its actin-binding domain, but this does not seem to be sufficient for the interconnection of individual Z-discs. It will be necessary to unequivocally identify specific myofibrillar proteins binding to plectin before such questions can be answered.

In summary, our study demonstrated that the expression of at least two high molecular mass plectin isoforms is highly conserved during muscle differentiation ranging from undifferentiated proliferating myoblasts to mature human skeletal muscle tissue. Our results also indicate that the association of plectin with Z-discs might play a role in aligning cross-striated myofibrils and in anchoring the Z-discs of neighboring myofibrils to each other, and that it is a prerequisite for the subsequent attachment of the three dimensional desmin-based intermyofibrillar cytoskeleton.

\section{Materials and Methods}

\section{Human Skeletal Muscle Cell Cultures}

Human skeletal muscle cells were isolated from normal adult human skeletal muscle biopsies, were cultured, and were differentiated into maturing and mature myotubes as described previously (Van der Ven et al, 1992; Van der Ven et al, 1993; Van der Ven and Fürst, 1997). The differentiation of spindle or polygonally shaped proliferating myoblasts was initiated by a switch to a low-nutrition medium. At different time points after the change of medium, differentiating cells were harvested for Northern or Western blot analysis by means of standard procedures or were fixed for 5 minutes in a 1:1 mixture of methanol and acetone at $-20^{\circ}$ and were then air-dried.

\section{Northern Blot Analysis}

Total RNA from cultured human skeletal muscle cells at various stages of differentiation was purified using the RNA Isolation Kit according to the instructions of the manufacturer (Stratagene, Heidelberg, Germany). Gel fractionation, RNA blotting, hybridization, and washing procedures were performed as described previously (Schröder et al, 1999). An expressed sequence tag (ID-NR: yg34f10.rl) corresponding to the $3^{\prime}$ end of the human plectin cDNA, which was provided by the I.M.A.G.E consortium (Lennon et al, 1996), was used as probe.

\section{Gel Electrophoresis and Immunoblotting}

Total protein extracts from cultured human skeletal muscle cells that were differentiated for 0 to 6 days were prepared as described previously (Schröder et al, 1999). SDS-PAGE using 5\% polyacrylamid gels, protein transfer, and visualization of proteins on membranes was also performed as described (Schröder et al, 1999). Immunoblotting of plectin was performed with guinea pig P2 antiserum $(1: 20,000)$ a peroxidasecoupled secondary antibody $(1: 30,000)$ and the Supersignal enhanced chemiluminescence system (Pierce, Rockford, Illinois). 


\section{Antibodies}

The following primary antibodies were used in this study: P2 guinea pig serum, an antiserum highly specific for plectin, that was raised against the carboxyterminal repeat domain 6 of human plectin (Schröder et al, 1999); T12, a mouse monoclonal antibody directed against an epitope of titin located close to the Z-disc (Fürst et al, 1988); pDes, a polyclonal rabbit antiserum raised against chicken gizzard desmin (Ramaekers et al, 1985); and RV 202, a mouse monoclonal antibody specific for vimentin (Ramaekers et al, 1987). The latter two antibodies were a kind gift of Dr. Gert Schaart, Maastricht, The Netherlands, and are available from Eurodiagnostica, Maastricht, The Netherlands.

\section{Immunofluorescence Microscopy}

For indirect immunofluorescence assays of cultured human skeletal muscle cells, standard procedures were used (Van der Ven et al, 1993). Isotype-specific secondary antibodies conjugated with fluorescein isothiocyanate, Cy2, or Texas Red were applied according to the recommendations of the manufacturers (Southern Biotechnology Associates, Birmingham, Alabama; Jackson Immunoresearch Laboratories, West Grove, Pennsylvania). Bleedthrough of any of the conjugates in the complementary channel was not observed. Controls included the omission of primary antibodies and a careful check for the specificity of the secondary antibodies. All specimens were examined, and pictures were digitally acquired with a Zeiss Axiophot microscope (Zeiss, Oberkochen, Germany) that was equipped with a cooled CCD camera or with a confocal laser scanning microscope (Leica TCS-NT, Bensheim, Germany).

\section{Acknowledgements}

The authors thank $\mathrm{Dr}$ I. Blümcke for his help with confocal laser scanning microscopy and Mrs. B. Mai for help with immunostaining.

\section{References}

Andrä K, Lassmann H, Bittner R, Shorny S, Fassler R, Propst $F$, and Wiche $G$ (1997). Targeted inactivation of plectin reveals essential function in maintaining the integrity of skin, muscle, and heart cytoarchitecture. Genes Dev 11:31433156.

Andrä K, Nikolic B, Stocher M, Drenckhahn D, and Wiche G (1998). Not just scaffolding: Plectin regulates actin dynamics in cultured cells. Genes Dev 12:3442-3451.

Bilak SR, Sernett SW, Bilak MM, Bellin RM, Stromer MH, Huiatt TW, and Robson RM (1998). Properties of the novel intermediate filament protein synemin and its identification in mammalian muscle. Arch Biochem Biophys 355:63-76.

Carlsson L, Price MG, Robson R, Breckler J, Wiche G, Li Z, Paulin D, and Thornell L-E (1999). Expression of IF-related proteins in desmin knock-out mice. J Muscle Res Cell Motil 20:109.
Chavanas S, Pulkkinen L, Gache Y, Smith FJ, McLean WH, Uitto J, Ortonne JP, and Meneguzzi G (1996). A homozygous nonsense mutation in the PLEC1 gene in patients with epidermolysis bullosa simplex with muscular dystrophy. J Clin Invest 98:2196-2200.

Dang M, Pulkkinen L, Smith FJ, McLean WH, and Uitto J (1998). Novel compound heterozygous mutations in the plectin gene in epidermolysis bullosa with muscular dystrophy and the use of protein truncation test for detection of premature termination codon mutations. Lab Invest 78:195204.

Doriguzzi C, Palmucci L, Mongini T, Bertolotto A, Maniscalco M, Chiado-Piat L, Zina AM, and Bundino S (1993). Congenital muscular dystrophy associated with familial junctional epidermolysis bullosa letalis. Eur Neurol 33:454-460.

Elliott CE, Becker B, Oehler S, Castanon MJ, Hauptmann R, and Wiche G (1997). Plectin transcript diversity: Identification and tissue distribution of variants with distinct first coding exons and rodless isoforms. Genomics 42:115-125.

Fürst DO, Osborn M, Nave R, and Weber K (1988). The organization of titin filaments in the half-sarcomere revealed by monoclonal antibodies in immunoelectron microscopy: $A$ map of ten nonrepetitive epitopes starting at the $Z$ line extends close to the M line. J Cell Biol 106:1563-1572.

Gache Y, Chavanas S, Lacour JP, Wiche G, Owaribe K, Meneguzzi G, and Ortonne JP (1996). Defective expression of plectin/HD1 in epidermolysis bullosa simplex with muscular dystrophy. J Clin Invest 97:2289-2298.

Granger BL and Lazarides E (1980). Synemin: A new high molecular weight protein associated with desmin and vimentin filaments in muscle. Cell 22:727-738.

Hemken PM, Bellin RM, Sernett SW, Becker B, Huiatt TW, and Robson RM (1997). Molecular characteristics of the novel intermediate filament protein paranemin. Sequence reveals EAP-300 and IFAPa-400 are highly homologous to paranemin. J Biol Chem 272:32489-32499.

Herrmann H and Wiche G (1987). Plectin and IFAP-300K are homologous proteins binding to microtubule-associated proteins 1 and 2 and to the 240-kilodalton subunit of spectrin. J Biol Chem 262:1320-1325.

Hijikata T, Murakami T, Imamura M, Fujimaki N, and Ishikawa $H$ (1999). Plectin is a linker of intermediate filaments to Z-discs in skeletal muscle fibers. J Cell Sci 112:867-876.

Lennon G, Auffray C, Polymeropoulos M, and Soares MB (1996). The I. M. A. G. E. Consortium: An integrated molecular analysis of genomes and their expression. Genomics 33:151-152.

Li Z, Mericskay M, Agbulut O, Butler-Browne G, Carlsson L, Thornell LE, Babinet C, and Paulin D (1997). Desmin is essential for the tensile strength and integrity of myofibrils but not for myogenic commitment, differentiation, and fusion of skeletal muscle. J Cell Biol 139:129-144.

Liu CG, Maercker C, Castanon MJ, Hauptmann R, and Wiche $G$ (1996). Human plectin: Organization of the gene, sequence analysis, and chromosome localization (8q24). Proc Natl Acad Sci U S A 93:4278-4283.

McLean WH, Pulkkinen L, Smith FJ, Rugg EL, Lane EB, Bullrich F, Burgeson RE, Amano S, Hudson DL, Owaribe K, McGrath JA, McMillan JR, Eady RA, Leigh IM, Christiano AM, and Uitto $J$ (1996). Loss of plectin causes epidermolysis bullosa with muscular dystrophy: cDNA cloning and genomic organization. Genes Dev 10:1724-1735. 
Niessen CM, Hulsman EH, Rots ES, Sanchez-Aparicio P, and Sonnenberg A (1997). Integrin alpha 6 beta 4 forms a complex with the cytoskeletal protein HD1 and induces its redistribution in transfected COS-7 cells. Mol Biol Cell 8:555-566.

Price MG and Lazarides E (1983). Expression of intermediate filament-associated proteins paranemin and synemin in chicken development. J Cell Biol 97:1860-1874.

Pulkkinen L, Smith FJ, Shimizu H, Murata S, Yaoita $H$, Hachisuka H, Nishikawa T, McLean WH, and Uitto J (1996). Homozygous deletion mutations in the plectin gene (PLEC1) in patients with epidermolysis bullosa simplex associated with late-onset muscular dystrophy. Hum Mol Genet 5:15391546.

Ramaekers F, Huysmans A, Schaart G, Moesker O, and Vooijs $P$ (1987). Tissue distribution of keratin 7 as monitored by a monoclonal antibody. Exp Cell Res 170:235-249.

Ramaekers FCS, Moesker O, Huysmans A, Schaart G, Westerhof G, Wagenaar SS, Herman CJ, and Vooijs GP (1985). Intermediate filament proteins in the study of tumor heterogeneity: An in-depth study of tumors of the urinary and respiratory tracts. Ann N Y Acad Sci 455:614-634.

Rezniczek GA, de Pereda JM, Reipert S, and Wiche G (1998). Linking integrin $\alpha 6 \beta 4$-based cell adhesion to the intermediate filament cytoskeleton: Direct interaction between the beta4 subunit and plectin at multiple molecular sites. J Cell Biol 141:209-225.

Ruhrberg C, Hajibagheri MA, Parry DA, and Watt FM (1997). Periplakin, a novel component of cornified envelopes and desmosomes that belongs to the plakin family and forms complexes with envoplakin. J Cell Biol 139:1835-1849.

Ruhrberg C, Hajibagheri MA, Simon M, Dooley TP, and Watt FM (1996). Envoplakin, a novel precursor of the cornified envelope that has homology to desmoplakin. J Cell Biol 134:715-729.

Ruhrberg C and Watt FM (1997). The plakin family: Versatile organizers of cytoskeletal architecture. Curr Opin Genet Dev 7:392-397.

Schröder R, Mundegar RR, Treusch M, Schlegel U, Blümcke I, Owaribe K, and Magin TM (1997). Altered distribution of plectin/ HD1 in dystrophinopathies. Eur J Cell Biol 74:165-171.

Schröder R, Warlo I, Herrmann H, van der Ven PFM, Klasen C, Blumcke I, Mundegar RR, Fürst DO, Goebel HH, and Magin TM (1999). Immunogold EM reveals a close association of plectin and the desmin cytoskeleton in human skeletal muscle. Eur J Cell Biol 78:288-295.

Seifert GJ, Lawson D, and Wiche G (1992). Immunolocalization of the intermediate filament-associated protein plectin at focal contacts and actin stress fibers. Eur J Cell Biol 59:138-147.

Smith FJ, Eady RA, Leigh IM, McMillan JR, Rugg EL, Kelsell DP, Bryant SP, Spurr NK, Geddes JF, Kirtschig G, Milana G, de Bono AG, Owaribe K, Wiche G, Pulkkinen L, Uitto J, McLean WH, and Lane EB (1996). Plectin deficiency results in muscular dystrophy with epidermolysis bullosa. Nat Genet 13:450-457.
Stappenbeck TS, Bornslaeger EA, Corcoran CM, Luu HH, Virata ML, and Green KJ (1993). Functional analysis of desmoplakin domains: Specification of the interaction with keratin versus vimentin intermediate filament networks. J Cell Biol 123:691-705.

Svitkina TM, Verkhovsky AB, and Borisy GG (1996). Plectin sidearms mediate interaction of intermediate filaments with microtubules and other components of the cytoskeleton. J Cell Biol 135:991-1007.

Takizawa $\mathrm{Y}$, Shimizu H, Rouan F, Kawai M, Udono M, Pulkkinen L, Nishikawa T, and Uitto J (1999). Four novel plectin gene mutations in Japanese patients with epidermolysis bullosa with muscular dystrophy disclosed by heteroduplex scanning and protein truncation tests. J Invest Dermatol 112:109-112.

Van der Ven PFM and Fürst DO (1997). Assembly of titin, myomesin and $M$-protein into the sarcomeric $M$ band in differentiating human skeletal muscle cells in vitro. Cell Struct Funct 22:163-171.

Van der Ven PFM, Schaart G, Croes HJ, Jap PHK, Ginsel LA, and Ramaekers FCS (1993). Titin aggregates associated with intermediate filaments align along stress fiber-like structures during human skeletal muscle cell differentiation. J Cell Sci 106:749-759.

Van der Ven PFM, Schaart G, Jap PHK, Sengers RC, Stadhouders AM, and Ramaekers FCS (1992). Differentiation of human skeletal muscle cells in culture: maturation as indicated by titin and desmin striation. Cell Tissue Res 270:189198.

Wiche G (1989). Plectin: General overview and appraisal of its potential role as a subunit protein of the cytomatrix. Crit Rev Biochem Mol Biol 24:41-67.

Wiche $\mathrm{G}$ (1998). Role of plectin in cytoskeleton organization and dynamics. J Cell Sci 111:2477-2486.

Wiche G, Gromov D, Donovan A, Castanon MJ, and Fuchs E (1993). Expression of plectin mutant cDNA in cultured cells indicates a role of $\mathrm{COOH}$-terminal domain in intermediate filament association. J Cell Biol 121:607-619.

Wiche G, Krepler R, Artlieb U, Pytela R, and Denk H (1983). Occurrence and immunolocalization of plectin in tissues. J Cell Biol 97:887-901.

Yang Y, Dowling J, Yu QC, Kouklis P, Cleveland DW, and Fuchs E (1996). An essential cytoskeletal linker protein connecting actin microfilaments to intermediate filaments. Cell 86:655-665 